\title{
THE PSYGHOLOGY OF CHARAGTER*-I.
}

\author{
By WILLIAM BROWN, London and Oxford.
}

Prof. W. McDougall's recent book, An Outline of Psychology, may be regarded as the latest of a series of expositions of the structure and functioning of the mind, but despite its manifest excellences there can be little doubt that in the future systematic psychologists will have to take very much more account of so-called ' deep analysis' than they have hitherto been able to do. In his Outline we have the most complete analysis of the mind up to date along the lines of ordinary normal psychology, using material and data obtainable by anyone who restricts his attention to the study of his own consciousness and of the behaviour of other normal human beings and animals. Deep analysis, however, is not content to observe the surface of the mind, but pushes enquiry further and further back; and, in pushing that enquiry back, obtains by its own methods a greater and greater wealth of material, and draws conclusions from that material according to certain laws, comparing it also with material obtained by close and prolonged studies of pathological cases. Such a method of deep analysis throws a somewhat different light on the whole matter. It is not that we wish to explain the normal in terms of the abnormal, but these great experiments made by nature upon the human mind do magnify certain lines of functioning, and so make them observable, whereas in the past they have been overlooked.

It will be remembered that McDougall's general conception of the structure of the mind is that it is built upon a foundation of instinctive dispositions. These dispositions are conative in nature, they show characteristics of purpose, and reveal themselves in consciousness as different forms of emotional activity ; so that we have, corresponding to various fundamental instincts, various fundamental forms of emotion. After these fundamental instincts have been discovered and enumerated, McDougall proceeds to describe what he calls secondary emotions, which are due to the simultaneous activity of two or more instinctive dispositions. As an example of such an emotional compound we may take the anger and disgust felt towards anyone who has been guilty of a mean action. That feeling carries with it two corresponding impulses : anger-to destroy or injure the person; and disgust-to keep clear of, and have nothing to do with, him. And then McDougall proceeds in his latest book to improve upon the system of emotions he gives in his Social Psychology by bringing in derived emotions ; and this is a very important class, because it shows that he is not unaware of modes of production of emotion which psychopathology has forced upon our notice for some years past.

* Abstract of a lecture delivered in the University of Oxford, February 2, 1925. 
These derived emotions are, for example, such emotions as hope, expecta-

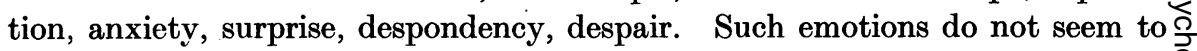
follow his rule of being the subjective aspect of instinctive activities. If응

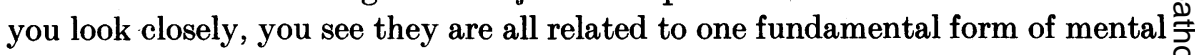
activity-desire. In fáct, they have been stated by A. F. Shand in his Foundations of Character, under the heading "Emotions of Desire." These $\stackrel{\vec{F}}{\stackrel{(}{\longrightarrow}}$ emotions are aroused in relation to the degree of success or failure of any desire in achieving or attaining its end. If the end seems likely to be attained, hope $\frac{\bar{O}}{\bar{N}}$ springs up in the person's mind; complete attainment brings joy. With $\frac{\bar{D}}{\bar{\Phi}}$ the possibility of failure there arises a feeling of anxiety; when the prospects $\frac{\mathbb{Q}}{2}$ of failure become more pronounced, despondency; when failure seems in- $\infty$ evitable, despair. Now, compare these emotions with that of anger, which $\vec{\circ}$ accompanies the combative instinct. Here in regard to the emotion of anger, $\vec{\omega}$ McDougall himself admits that it is related to or results from the thwarting of other instinctive activities. If these activities are thwarted or hindered $\overline{0}$ the feeling of anger may be aroused or stimulated. But he will not admit is that a similar situation is to be found in regard to the emotion of fear. $\mathrm{He}$ correlates the emotion of fear with the instinct of escape, and he considerg that it is fully explainable in terms of the instinct of escape.

The obvious objection to such a view is that, so far as the instinct of escape is working according to plan, the individual does not experience fear. The man escaping from his pursuers is concentrating his attention on what he is doing, e.g., leaping from crag to crag; he has no time to experience fea. $\overrightarrow{0}$ In a way McDougall admits that he may not really feel fear at that time, bu insists that the fear is there if he had the opportunity to look more close into his mind. But it is not a question of not noticing the fear ; it is not there at all. When a man is successful in his escape he may not find any trace of fear. Soldiers have often verified this in the course of a war. They are so $\frac{๊}{\mathrm{D}}$ busy carrying out their job that they have not had time or occasion to feel fear. But if they are in a tight corner where no means of escape offers itself, they do feel fear. Fear, as such, in the main is similar to members of this class of derived emotions. It arises from the thwarting of the instinct of escape. Besides that, I have no doubt that it tends to be aroused when danger threatens, when the instinct of escape is also aroused. A certain amount of fear arises? as a danger signal. The mind is thus woken up, but it passes into much more extreme forms of fear and terror when the means of escape are cut off or are problematical.

And then, if we look down McDougall's lists of primary emotions, opposite ó to the gregarious instinct we find that he puts, not the emotion corresponding to the gregarious instinct, whatever that may be, but the various emotions that arise in the mind when the gregarious instinct is thwarted or interfered with. ON If the gregarious animal is separated from the herd or flock that animal feels $N$ restless, lonely and greatly disturbed; and this emotion seems to be what $\mathrm{N}$ McDougall has in mind as the emotion accompanying the functioning $\mathrm{cf} \underset{\sigma}{\sigma}$ 
gregariousness. I think it would rather be a feeling of pleasure that people seem to experience in going e.g. to a political meeting or attending a theatre or concert, a feeling of union with their fellows; but the fact that he has to emphasise in his list just the contrary emotions-those that arise when the instinct is not satisfied-gives us a further hint of a kind of classification which is different from his own, and which is more in harmony with the usual view of emotion-the view that it is a kind of friction in the mental machinery. This, no doubt, was at the back of the minds of the philosophers of old who considered the state of being free from emotion as the happiest state ; otherwise we have not complete control of our mind; it is a nuisance to feel emotion.

Probably the truth lies between the two extremes. A great deal of emotion is undoubtedly the result of mental conflict, although we must admit that, even where there is no conflict, in certain cases there is emotion. It would not be difficult to pick out from McDougall's list those instinctive emotions and dispositions which seem to be valid independently of any kind of conflict, but they would be small in number. The majority of them do arise from conflict. Of course, in psychopathology this factor of mental conflict is all-important. The symptoms of the psychoneurotic can be expressed in general as a perverted or inadequate means of solving, overcoming, or escaping from the stress of mental conflict—of saving the patient from himself. We shall have to consider that more fully later. Keeping to our task of dealing with McDougall's system, we pass from this important class of derived emotions to the emotions that are aroused within a sentiment. A sentiment is an organised system of emotional dispositions centred about the idea of some object, and certain emotional experiences can only be felt when a sentiment of that kind is present. For example, the emotion of reproach is different from the emotional experience of anger; and yet it is not a blending of anger with any other specific emotion. It is the arousing of the emotion of anger within the sentiment of love. If a stranger does us an injury or displeases us in any way, we simply feel anger towards him ; but, if a dearly loved friend does something to hurt our feelings or disappoint us, we feel reproach. There is the feeling of anger, but softened by the sentiment of affection or love, which involves the potentiality of a large number of different emotions experienced under different circumstances. Only where a sentiment is present would such feelings be experienced.

Our present purpose, however, is not to enumerate the different forms of feeling, but to consider general principles of mental organisation. McDougall has applied the doctrine of the sentiments in dealing with the difficult problem of volition, particularly in cases of so-called hard choice, where the individual is moved simultaneously in two directions ; in one direction by the very intense native propensity of a fundamental instinct accompanied by a strong feeling tone, and in an opposite direction by an impulse of a more ideal nature, which seems to carry less energy with it, and yet may win the day. William James, faced with this problem, explained it in terms of a fiat of the will. 
His view was that, if this propensity on the one side was stronger in itself than the motive to act according to an ideal of conduct, the ideal motive being accompanied by a much less vivid feeling would be overwhelmed by this strong native propensity; but that the man of strong will overcomes such native propensity by bringing in also something additional, a fiat of the will. McDougall is not satisfied with this solution. He asks whence comes the energy of this effort of the will, and considers that he can find it in the energy represented by a fundamental sentiment which he calls the 'self-regarding sentiment.' A man has strength of character in so far as he has organised his emotional dispositions about the idea of himself in the form of the selfregarding sentiment ; and in a case of hard choice, he brings this self-regarding sentiment into activity. This is the source of the energy which, as an effort of will, reinforces the individual's ideal impulse in its conflict with native propensity.

This is perhaps a more detailed and accurate explanation of volitional activity than has hitherto been given in psychological text-books. It certainly goes one better than James, and at any rate it has the courage of entering into detail; but yet it strikes one as being far too mechanical to be a worthy description of such a complicated organisation as that of the human mind The truth probably is that the will-volition-is the entire mind in action in its most complete development, as a harmoniously working unity, and that within this unity of the mind there are various levels corresponding to different successive stages of development of mental power. The lowest level is the animal level of instinct and appetite. Above that you come to the level of intellectualism, or generalisation of wishes and desires; and, through the interaction, as it were, of knowledge on the one side and various individual conative systems of the mind on the other, there develops an organisation possessing and showing a greater and greater degree of freedom in that it becomes more and more relatively independent of external events as such. That is to say, the mind becomes more and more self-determined in the course of its development and thus manufactures freedom. Freedom is a characteristic that develops. The mind starts with a minimum of freedom which is present in the simplest form of mental reaction, i.e., in the purposiveness which is to be seen in all behaviour. It develops this in its own way, and, when you have a case of so-called hard choice occurring, you really have one of the lower levels of organisation struggling against the higher organisation; and, though on the surface, in consciousness, it may make a great deal of fuss, as it were, and may seem to have a great deal of power at its disposal, yet actually it is very much weaker than the rest of the mind. The latter has reserves of power. which deal with it; just as after a wound, although the bodily organisation shows a rise in temperature and the wound itself looks ugly and attracts attention, nevertheless, the rest of the body, the healthy part, is destined to win the battle with it.

We must now turn to another side of the structure of the mind-the 
cognitive side. Here we have a further very illuminating suggestion from Prof. McDougall. He cogently argues that an individual's knowledge accumulates in the form of cognitive dispositions. Just as the active side of his mind rises from the better organisation of the conative dispositions of instinct, so on the side of knowledge the individual gradually builds up an organised system of cognitive dispositions. He does this, not so much by observing different individual objects in space, comparing them with one another and so getting more and more general ideas, as we say, of objects ; passing, for instance, from different kinds of dogs to a conception of dogs in general, then dogs, cats, horses, etc., on to the idea of animals in general. Rather, he begins in the other way with a generalised experience, and learns to differentiate that experience by noting in the course of his life more and more carefully the points of difference between objects. The tendency in the young child is to generalise, but not in the logical sense. It is inclined to overlook differences at first and to classify different things together; then gradually, by noticing differences in relation to its needs (because it only notices owing to its interest in the object), it learns to appreciate variety. But beside this process of differentiation there occurs assimilation and apperception, where resemblances are observed between different objects ; so that by slow degrees the total system of knowledge of the individual takes a form analogous to that of a tree with its main stem, branches, twigs and terminal leaves, corresponding to the general conception of objects, and the existence of the different kinds of laws in different sciences. This is merely to say that this systematic knowledge is a systematic arrangement, as it were, of cognitive dispositions ; and the way in which the individual acquires this systematic arrangement of cognitive dispositions is through the processes of differentiation, apperception and association.

Nevertheless, in addition to this kind of system, you have also the historica system. The individual lives his life from day to day, various incidents occur, these incidents are in a certain sense retained in memory, and knowledge is laid down, as it were, in that form. This historical kind of experience is not, however, wholly unrelated to the other form, which is not itself historical, but, as it were, sub specie cternitatis-the general knowledge of laws and properties, etc., of things and objects, animate and inanimate, and not the actual working of the mind at any point which it has reached. Take an individual at the age of twenty-six or so. He has these various cognitive dispositions laid down in the course of his life, and his reaction to his environment has reference to both these systems. He reacts according to his own individual experience, and also according to his scientific knowledge, which has been acquired partly by himself, by experiment, etc., and partly from what he has read in books. It is essential to note that both systems of cognitive dispositions have become linked up with conative dispositions. He has acquired likes and dislikes for different branches of knowledge and also in relation to incidents in his own life. And it is when we consider the relation of 
the cognitive dispositions to conative dispositions that we are facing the rea problem of voluntary action.

Individual acts, then, occur with reference to knowledge, on the one side and wishes, desires, strivings, etc., on the other. These are the sentiments,, to which we have been already referred, examples of inter-organisation of cognitive and conative dispositions. But we find that in the individual $\overline{0}$ besides these healthy sentiments, which are normal features of the mind, $\stackrel{\circ}{\circ}$ there is a tendency for abnormal unhealthy mental systems to be produced in $\stackrel{5}{5}$ the mind corresponding to painful experiences of the past. The individual $\mathbb{R}$ has had, e.g., a painful experience of a frightening nature. He has beenco disturbed by a certain event in his life, and later on his whole mind tends to $\vec{\circ}$ react to analogous situations with reference to the previous fright. Such $\vec{\omega}$ abnormal systems are called complexes, and the word complex should, I think. be restricted to abnormal systems. We should not use the term complexज़ if we mean the normal systems for which the technical term would be senti-is ment. But where we find pathological disturbance of the individual's judg $\vec{\sim}$ ment, which puts him out of harmony with his environment and prevents himiv from reacting adequately to a situation, then we would call it a comple ${ }^{\circ} . \omega$ He has had an unfortunate experience, and has developed, let us say, a complex $\vec{x}$ 의 against a certain type of individual, so that he does not do himself justige later on when he meets individuals of the same profession or class as the a who has disturbed his mind previously. A complex is essentially of the natuge $\vec{e}$ of a fixation, anchoring the mind down and preventing it from movitign onward, whereas we can look upon sentiment as a healthy growth of teoc mind. Likes and dislikes with reference to adequate experience, i.e., the various sentiments, grow by including a larger and larger number of objectso within themselves, and by being adjusted more and more adequately to these objects. Through them the mind gains greater and greater freedom, a wider $\stackrel{\circ}{a}$ scope of activity, and a greater and greater degree of smoothness, of harmonious working. A complex, on the other hand, ties the individual down to the accident that aroused the complex ; it is a kind of precipitation of the mind.o The mind is held down and cannot develop further. Other parts of the mind do go on developing, but that particular part is fixed in such a way that wheno the complex is struck on, as we say, that is, stimulated by some chance event, $\frac{}{3}$ the whole mind reacts just exclusively and explosively to that complex. The individual explodes with anger without clearly knowing why he should be angry.

We may now ask : why should there be this difference between complexes? and sentiments? It is the difference between repression and unrepressionthe complex is repressed experience. It is not normal, not healthy, not fully justified; it has not been adequately faced by the individual but has been $\widetilde{N}$ held in check in a quasi-mechanical way. He has lost the power of normal N integration of consciousness. Sentiment can, under appropriate conditions, produce the various emotions according to rule, but in the case of a complex what is repressed is, not so much the emotion, but rather the cognitive disposi- -0 
tion, i.e., the original experience is withdrawn from attentive control. The mind has lost the faculty of recalling the original experience, although the corresponding emotional reaction can be rearoused. In certain situations, a person flies into a rage and does not fully realise why. He acts mechanically, like an automaton, instead of like a free human being. You analyse his mind in order to overcome the repression, to bring these forgotten experiences into full consciousness, and in that way the complex is got rid of.

And then the interesting question arises about the relationship of complexes to sentiments as regards analysis. Complexes can be dealt with by analysis; you can resolve a complex. Now can the same thing be done with our sentiments? Theoretically it might be possible. We might look upon sentiment as a much more fundamental, thoroughgoing, deeply-founded system of interests, a strong organisation which needs very deep and prolonged analysis for disintegration. Friendships for different people and interests which we have formed in different kinds of subjects or causes or ideals, ethical, aesthetical, etc.-all these are of the nature of sentiments. In a long analysis, they might possibly be interfered with. I think we must leave it as a possibility which will be decided empirically in the course of further experience of long analyses. We know that a number of people have been analysed for a very long time, and some are still being analysed; and it is quite probable that, in their enthusiasm for psychoanalysis, some psychoanalysts will persevere with analysis of their clients-subjects who are not necessarily patients-for longer and longer periods of time. Short analyses may extend over six months or more, deeper analyses may go on for two or three years or even longer, and it would be interesting to see what the effects of such analyses upon sentiments are. One meets with special cases from time to time where the analysis has proved to be extremely disturbing, where the individual has needed further help to restore the balance of his mind. We know also, and are prepared for, the possibility that, where patients are on the verge of severe mental breakdown, an analysis might suffice to push them over the border. It is an obvious danger that every psychoanalyst would admit. It is possible that there are limits to analysis, though on the face of it, this seems fairly improbable. A person analysed may have derived a certain amount of benefit, not only as regards the symptoms which he may have shown, but also in getting a deeper insight into his mind, and learning to use it more and more adequately by getting rid of the effects of chance incidents of the past, i.e., his various complexes; and then, with a continuation of the analysis there might be a danger of interfering with his healthy sentiments. As far as one can make out, such a question as that does not seem to interest the enthusiastic followers of Freud in analysis. They speak of complete analysis, as if an individual can go right through with the analysis and come out, as it were, on the other side a stronger and better man, and yet they bring forward no conclusively satisfactory reasons for this view.

As regards terms, therefore, we can regard complexes as pathological 
formations analogous in structure to sentiments of the normal mind. In both cases there is a union or systematisation of cognitive and conative dispositions, and they both point forward to the general problem of freedom or self-determination of the mind, and the general problem of volition. McDougall's theory of volition in terms of the self-regarding sentiment is clearly a very important generalisation which, to a certain extent, does fit in with what can be said about disturbance of volition in pathological cases through the existence of complexes ; but when we come to deal with the mind from the point of view of ethics and metaphysics, as distinct from the merely psychological point of view, we may feel more firm in our suspicion that the explanation is a far too mechanical one.

( $T$ 'o be continued) 